\title{
Karakterisasi Senyawa Aktif Antibakteri Ekstrak Air Bunga Kecombrang (Etlingera elatior) Sebagai Bahan Pangan Fungsional
}

\author{
${ }^{1}$ Dede Sukandar, ${ }^{2}$ Nani Radiastuti, ${ }^{3}$ Ira Jayanegara, ${ }^{2}$ Adeng Hudaya \\ ${ }^{1)}$ Program Studi Kimia ${ }^{2)}$ Program Studi Biologi Fakultas Sains dan Teknologi \\ UIN Syarif Hidayatullah Jakarta, Jalan Ir. H. Juanda No 95 Ciputat 15412 Jakarta Telp. (62-21) 7493606 \\ ${ }^{3)}$ Badan Pengkajian dan Penerapan Teknologi, BPPT Jakarta \\ e-mail: d_sukandar@hotmail.com
}

\begin{abstract}
Abstrak
Telah dilaporkan penelitian mengenai aktivitas antimikroba ekstrak air bunga kecombrang (Etlingera elatior). Penelitian ini bertujuan memberikan bukti ilmiah keunggulan tanaman kecombrang sebagai bahan pangan fungsional.. Pengujian aktivitas antibakteri dilakukan menggunakan metode difusi cakram dan analisa komponen kimia dengan kromatografi GCMS. Ekstrak air bunga kecombrang bersifat antibakteri terhadap E. Coli (zona hambat 4,8 $\mathrm{mm} /$ konsentrasi $60 \%$ ) dan S. Aureus (zona hambat 6,87 mm, konsentrasi 20\%). Ekstrak air bunga kecombrang memiliki komponen utama1-dodekanol ( $\mathrm{tR}=11,60$, area=11,73, kemiripan $95 \%$ ), 3metil-1-okso-2-buten 1-( $2^{1}, 4^{1}, 5^{1}$-trihidroksi fenil) $(\mathrm{tR}=13,02$, area=3,17 kemiripan $57 \%)$ dan 1 tetradekena $(\mathrm{tR}=13,26$, area $=6,03$, kemiripan $98 \%$.
\end{abstract}

Kata Kunci: kecombrang (Etlingera elatior), pangan fungsionl, dan antibakteri

\begin{abstract}
A research of microbial activity from water extract of kecombrang flower ( Etlingera elatior) have been reported. This research aim to give erudite evidence excellence of kecombrang flower upon which the functional food. Examination of antibacterial with disk diffusion methode and chemical component analyses use GCMS. Water extract flower of kecombrang flower have antibacterial activity to E. Coli ( zona of inhibition $4,8 \mathrm{~mm}$, at concentration $60 \%$ ) and S. Aureus ( zona of inhibition $6,87 \mathrm{~mm}$, at concentration $20 \%$ ). Water extract of kecombrang flower have especial component 1-dodekanol ( $\mathrm{tR}=11,60$, area=11,73, similarity at $95 \%)$, 3-metil-1-oxo-2-buten 1$(21,41,51$-trihidroxyl phenil) $(\mathrm{tR}=13,02$, area $=3,17$, similarity at $57 \%)$ and 1 -tetradecene $(\mathrm{tR}=$ 13,26 , area $=6,03$, similarity at $98 \%$.
\end{abstract}

Keyword: kecombrang ( Etlingera Elatior), food fungsional and antibacterial

\section{PENDAHULUAN}

Seiring dengan makin meningkatnya kesadaran masyarakat akan pentingnya hidup sehat, tuntutan konsumen terhadap bahan pangan juga bergeser. Bahan pangan yang kini banyak diminati konsumen bukan saja yang mempunyai komposisi gizi yang baik serta penampakan dan cita rasanya menarik, tetapi juga harus memiliki fungsi fisiologis tertentu bagi tubuh, seperti dapat menurunkan tekanan darah, kadar kolesterol, dan kadar gula darah, serta meningkatkan penyerapan kalsium (Astawan 2003). Dewasa ini telah banyak dikembangkan produk pangan yang memadukan antara fungsi nutrisi dan kesehatan, yang sering disebut pangan fungsional. Pangan fungsional merupakan produk pangan yang memberikan keuntungan terhadap kesehatan. Pangan fungsional dapat mencegah atau mengobati penyakit (Goldberg, 1994).

Tanaman rempah dan obat mempunyai potensi besar sebagai sumber makanan dan minuman fungsional seiring dengan makin tingginya kesadaran masyarakat akan pentingnya menjaga kesehatan. Bagi konsumen, pangan fungsional bermanfaat untuk mencegah penyakit, meningkatkan 
imunitas, memperlambat proses penuaan, serta meningkatkan penampilan fisik. Bagi industri pangan, pangan fungsional akan memberikan kesempatan yang tidak terbatas untuk secara inovatif memformulasikan produk-produk yang mempunyai nilai tambah bagi masyarakat. Selanjutnya bagi pemerintah, adanya pangan fungsional akan menurunkan biaya untuk pemeliharaan kesehatan masyarakat (Winarti, 2005).

Salah satu tanaman rempah dan obat yang memiliki potensi sebagai pangan fungsional yang berfungsi sebagai antibakteri adalah kecombrang (Etlingera elatior). Kecombrang merupakan salah satu jenis tanaman rempah rempah yang sejak lama dikenal dan dimanfaatkan oleh manusia sebagai obat-obatan (Hidayat dan Hutapea 1991). Menurut Hasbah et al. (2005) tanaman kecombrang dapat dipakai untuk mengobati penyakit-penyakit yang tergolong berat yaitu kanker dan tumor. Bunga dari tanaman ini bisa digunakan sebagai bahan kosmetik alami dimana bunganya dipakai untuk campuran cairan pencuci rambut dan daun serta rimpangnya dipakai untuk bahan campuran bedak oleh penduduk lokal (Chan et. al., 2007).

Kecombrang (Etlingera elatior) merupakan salah satu keluarga Zingiberacea yang asli Indonesia. Tanaman ini dikenal dengan berbagai nama antara lain "kencong" atau "kincung" di Sumatra Utara, "kecombrang" di Jawa, "honje" di Sunda, "bongkot" di Bali, "sambuang" di Sumatra Barat dan "bunga kantan" di Malaysia. Orang barat menyebut tanaman ini torch ginger atau torch lily karena bentuk bunganya yang mirip obor serta warnanya yang merah memukau (Gambar 1). Beberapa orang juga menyebutnya dengan nama philippine waxflower atau porcelein rose mengacu pada keindahan bunganya. Tanaman ini adalah tanaman asli Indonesia yang dibuktikan dengan suatu studi etnobotani di pulau Kalimantan, dimana $70 \%$ dari spesies yang ada mempunyai nama lokal lainnya di pulau tersebut dan lebih dari $60 \%$ spesies yang ada mempunyai paling tidak satu manfaat yang digunakan oleh penduduk pulau Kalimantan.

Bunga kecombrang memiliki beberapa keunggulan antara lain sebagai edible flower dan memiliki altivitas antibakteri perusak pangan. Pengembangan produk makanan berbasis kecombrang akan dapat memberikan gambaran pada masyarakat tentang aplikasi bunga kecombrang sebagai bahan pangan fungsional (Winarti dan Nurdjanah, 2005). Oleh karena itu, perlu dilakukan penelitian tentang aktivitas antibakteri dari ekstrak air bunga kecombrang.

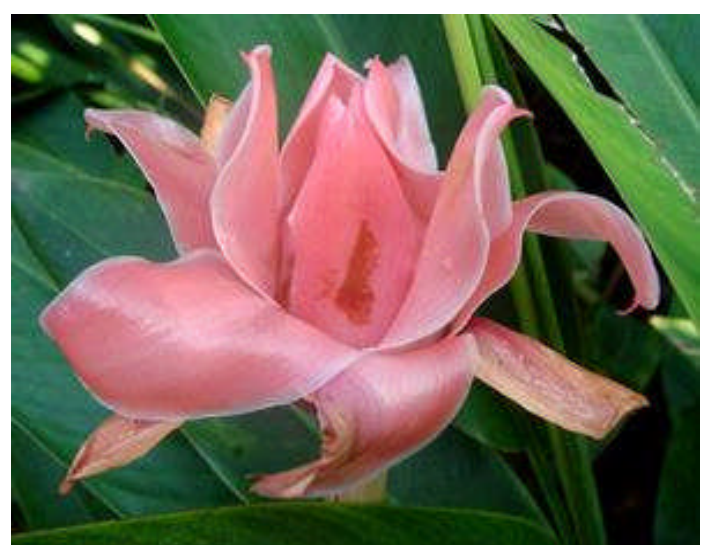

Gambar 1. Bunga kecombrang (Etlingera elatior).

\section{METODE PENELITIAN}

Umum. Ekstraksi dilakukan dengan maserasi selama 3 x 24 jam,. pengujian aktivitas antibakteri dengan metode difusi cakram dan analisa komponen kimia dalam ekstrak bunga kecombrang menggunakan alat Gas Chromatography-Mass Spectroscopy (GCMS).

Bahan. Bahan kimia menggunakan kloramfenikol dan bahan alam berupa bunga kecombrang.

Medium. Medium pemeliharaan bakteri Nutrient Agar (NA, Pronadisa), Nutrient Broth (NB, Pronadisa), Plate Count Agar (PCA, Pronadisa)

Ekstraksi. Sebanyak 150 gram sampel bunga dan gaun kecombtang kering dimaserasi dalam 1 liter pelarut akuades selama 3 x 24 jam. Hasil ekstraksi disaring, dipekatkan menggunakan rotary evaporator dan selanjutnya dipergunakan pada pengujian aktivitas antimikroba dan analisa komponen kimia. 


\section{Pengujian Antibakteri}

\section{Pembuatan Media NA}

Sebanyak 2,4 g NA ditimbang dan dilarutkan dalam $100 \mathrm{ml}$ akuades, selanjutnya dipanaskan sehingga NA larut, dan dituang ke dalam beberapa tabung reaksi masing-masing sebanyak $5 \mathrm{ml}$ dan sisanya dituang ke dalam tabung Erlenmeyer $100 \mathrm{ml}$. Media disterilisasi dalam autoklaf pada suhu $121{ }^{\circ} \mathrm{C}$ selama 15 menit. Setelah media steril, dimiringkan dan dibekukan. Media dalam tabung Erlenmeyer yang sudah disterilisasi dituang ke dalam cawan petri steril untuk membuat agar plat;

\section{Peremajaan Biakan}

Bakteri yang akan digunakan diremajakan sebanyak 3 biakan murni, 1 sebagaai biakan stok dan 2 sebagai biakan kerja. Biakan tersebut ditumbuhkan pada agar miring NA selama 24 jam pada suhu $37^{\circ} \mathrm{C}$;

\section{Persiapan Suspensi Sel Bakteri}

Biakan yang telah tumbuh pada agar miring NA ditambahkan dengan $5 \mathrm{ml}$ akuades steril. Pengerikan dilakukan menggunakan ose, sehingga diperoleh suspensi spora, kemudian dikocok menggunakan vortex supaya homogen. Suspensi spora dimasukkan ke dalam erlenmeyer $100 \mathrm{ml}$ steril;

\section{Perhitungan Jumlah Sel}

Suspensi sel bakteri diencerkan sampai pengenceran $10^{-7}$. Kemudian disebar pada permukaan NA steril dalam cawan petri. Inkubasi dilakukan pada suhu $37^{\circ} \mathrm{C}$ selama 7 hari. Cara menentukan jumlah mikroorganisme per $\mathrm{ml}$ suspensi dilakukan dengan membagi jumlah koloni terhitung dengan volume suspensi yang diinokulasi dan dibagi dengan pengenceran yang digunakan;

\section{Pengujian Antibakteri dengan Metode Difusi Cakram}

1 ose biakan bakteri diambil kemudian dimasukkan kedalam $5 \mathrm{ml}$ media NB dan dihomogenkan setelah itu diinkubasi selama 7,5 Jam. Setelah 7,5 Jam diambil sebanyak 0,1 ml kemudian dimasukkan kedalam 10 ml NA cair dalam tabung dan dihomogenkan kemudian dituang kedalam petri. Ekstrak dengan berbagai konsentrasi sebanyak $0,03 \mathrm{ml}$ diambil menggunakan mikropipet $0,01 \mathrm{ml}$ pada kertas cakram steril berdiameter $1,6 \mathrm{~cm}$ kemudian ditanam pada media NA padat dalam petri. Setelah itu diinkubasi selama 24 Jam pada suhu $37^{\circ} \mathrm{C}$. Konsentrasi yang digunakan dalam pengujian ini adalah $20 \%$, $40 \%, 60 \%$, $80 \%$ dan $100 \%$ dimana pada konsentrasi tersebut hasil zona hambat ekstrak aur bunga dan daun kecombrang akan dibandingkan dengan konsentrasi kontrol kloeamfenikol dan aquades;

\section{Pengujian Waktu Daya Hambat Antibakteri terhadap Bakteri}

Medium agar (NA) sebanyak $10 \mathrm{ml}$ dicairkan dalam penangas air, kemudian didinginkan sampai suhunya kurang lebih $40^{\circ}$ C. Sebanyak $1 \mathrm{ml}$ berbagai minyak atsiri dengan berbagai konsentrasi dimasukkan ke medium agar NA steril, kemudian distirrer. Sebanyak $0,1 \mathrm{ml}$ suspensi biakan bakteri (pengenceran $10^{6}$ ) diteteskan ke dalam cawan petri steril. Medium agar dituangkan secara aseptik ke dalam setiap cawan petri yang sudah ditetesi suspensi biakan bakteri, diratakan dengan cara menggoyang dan dibiarkan mengeras. Biakan diinkubsi selama 24 jam, 48 jam dan 72 jam pada suhu kamar, kemudian di lakukan perhitungan jumlah koloni.

\section{Analisa GCMS}

Ekstrak air bunga dan daun kecombrang diidentifikasi kandungan kiminya menggunakan GC-MS Agilent Agilent 19091S-436. menggunakan kolom polar HP5MS $0.25 \times 60 \times 0.25 \mathrm{~mm}$, suhu oven $\left(70^{\circ} \mathrm{C}-\right.$ $\left.325^{\circ} \mathrm{C}\right)$, Interface $\left(290{ }^{\circ} \mathrm{C}\right)$, detektor $\left(250^{\circ} \mathrm{C}\right)$ kontrol mode (split), tekanan (16.30 psi), column flow $(1.0 \mathrm{ml} / \mathrm{min})$, split ratio $(50: 1)$, total flow (49,3 $\mathrm{ml} / \mathrm{min})$, gas $(\mathrm{He})$, gas saver (On), dan detektor (MSD).

\section{HASIL DAN PEMBAHASAN}

Ekstrak yang dihasilkan sebanyak 102 $\mathrm{ml}$ ekstrak kental hasil maserasi 150 gram serbuk bunga kecombrang dalam $2500 \mathrm{ml}$ akuades. Hasil ekstraksi daun kecombrang (Etlingera elatior) secara maserasi dengan menggunakan air menghasilkan $59 \mathrm{ml}$ ekstrak dari 90 gram daun kecombrang kering dan 
$1500 \mathrm{ml}$ akuades. Selanjutnya kedua ekstrak tersebut digunakan untuk pengujian aktivitas antibakteri dan analisa GCMS.

Bakteri uji yang digunakan dalam uji antibakteri ini adalah E.coli (sebagai gram negatif) dan $S$. aureus (sebagai gram positif). Pada uji antibakteri ektrak air bunga kecombrang (Etlingera elatior) ini tidak menghitung kurva pertumbuhan terlebih dahulu. Kurva pertumbuhan E. Coli dan $S$. Aureus mengacu kepada penelitian sebelumnya yang dilakukan Sukandar, et.al. (2010).

Menurut Sukandar, dkk. (2010) Midlog atau titik pertengahan antara fase log dengan fase stasioner E. coli berada pada menit ke450. Sedangkan puncak pertumbuhan $S$. aureus berada pada menit ke-600. Titik midlog ini digunakan untuk uji antibakteri, pada titik tersebut bakteri berada pada puncak pembelahan sel. Setelah itu, bakteri berada pada fase stasioner dimana jumlah sel yang tumbuh hampir sama dengan jumlah sel yang mati dan akhirnya bakteri mengalami penurunan jumlah sel, hal ini diakibatkan oleh nutrisi yang semakin berkurang atau terakumulasinya limbah metabolisme.

Selain dengan penentuan kurva tumbuh bakteri, pertumbuhan bakteri dapat juga diamati melalui perhitungan jumlah koloni bakteri yang diambil dari waktu midlog pada masing-masing bakteri tersebut. Perhitungan jumlah koloni bakteri sebelumnya dilakukan pengenceran pada media cair sebanyak 3 kali dari pengenceran terakhir yaitu $10^{-4}, 10^{-5}, 10^{-6}$ kemudian disebar pada media agar.

Perhitungan jumlah koloni harus memenuhi persyaratan jumlah koloni 30-300. Pada pengenceran $10^{-4}$ jumlah $E$. coli lebih dari 300 koloni atau tidak bisa untuk dihitung (TBUD), berarti pengenceran yang dilakukan terlalu rendah. Sedangkan, pengenceran $10^{-5}$ dan $10^{-6}$ sesuai dengan perhitungan $30-300$ koloni dan $S$. aureus masing-masing pengenceran sesuai dengan perhitungan 30300 koloni (Waluyo, 2008).

Setelah diketahui jumlah koloni bakteri pada masing-masing pengenceran, maka jumlah inokulum (sel/ml) pada masing-masing bakteri dapat diketahui. Berdasarkan hasil perhitungan jumlah koloni bakteri, jumlah inokulum E.coli dan S.aureus berturut-turut adalah: $1,62.10^{7} \mathrm{sel} / \mathrm{ml}$ dan $8.56 .10^{7} \mathrm{sel} / \mathrm{ml}$.

Aktivitas antibakteri diukur berdasarkan diameter zona hambat ekstrak air bunga kecombrang terhadap bakteri E. Coli dan $S$. Aureus ditampilkan pula pada gambar berikut.

\section{Grafik Diameter Zona Hambat Ekstrak Air Bunga Kecombrang (Etlingera elatior)}

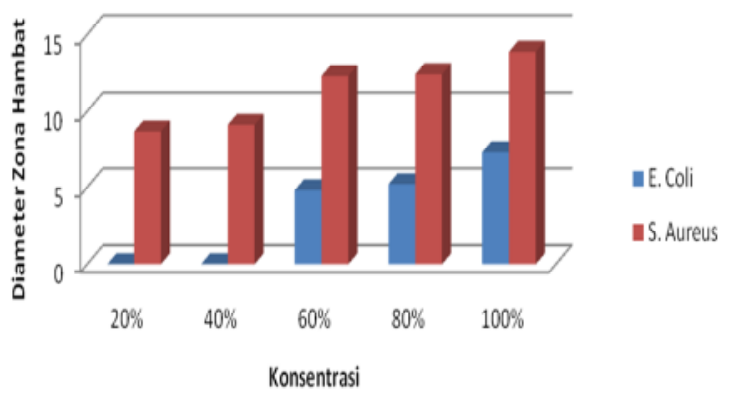

Gambar 2. Diameter zona hambat pertumbuhan bakteri oleh ekstrak air bunga kecombrang (Etlingera elatior)

Pada konsentrasi $20 \%$ ekstrak bunga kecombrang (Etlingera elatior) sudah mampu menghambat pertumbuhan bakteri $S$. areus ditandai terbentuknya zona hambat (zona bening) disekitar kertas cakram dengan diameter zona hambat $8.66 \mathrm{~mm}$. Sedangkan pada konsentrasi 20\% ektrak air bunga kecombrang belum mampu menghambat pertumbuhan E. coli. Pertumbuhan E. coli terhambat pada konsentrasi $60 \%$ dengan ratarata diameter zona hambat $7.15 \mathrm{~mm}$.

Diameter zona hambat yang didapatkan dari kedua bakteri uji terdapat perbedaan sesuai dengan besarnya konsentrasi yang diberikan. Semakin rendah konsentrasi yang diberikan, maka semakin kecil diameter zona hambat yang terbentuk oleh bakteri uji, karena semakin kecil konsentrasi maka zat aktif yang terlarut pada ektrak air bunga kecombrang semakin sedikit pula. Semakin tinggi konsentrasi yang diberikan, maka semakin luas pula diameter zona hambat yang terbentuk oleh bakteri uji. Perbedaan zona hambat pada 
S. aureus pada konsentrasi $60 \%, 80 \%$, dan
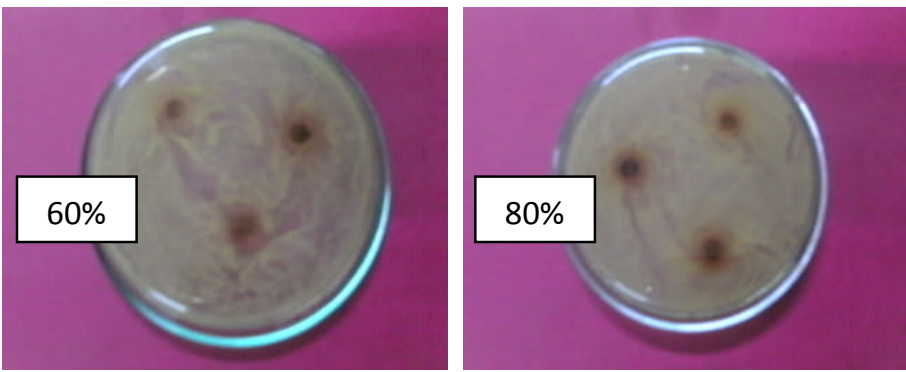

100\% dapat dilihat pada gambar berikut:

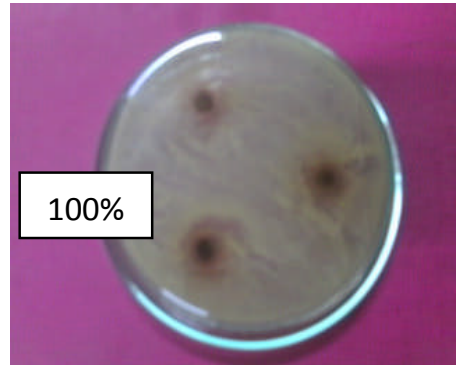

Gambar 3. Diameter zona hambat S.aureus ekstrak air bunga kecombrang konsentrasi 60\%, 80\% dan 100\%

Terbentuknya zona hambat terhadap $S$ .aureus pada konsentrasi 20\% sedangkan zona hambat E. coli terbentuk pada konsentrasi $60 \%$. Hal ini dikarenakan ada perbedaan golongan bakteri yang diujikan. S. aureus merupakan gram positif yang memiliki stuktur peptidoglikan lebih kompleks dan kandungan lipid yang lebih rendah dibandingkan dengan E. coli., sehingga dinding sel $S$. aureus lebih mudah dirusak oleh senyawa aktif ekstrak air bunga kecombrang daripada E. coli.

\section{Kontrol Positif}

Dalam pengujian antibakteri ekstrak air bunga kecombrang (Etlingera elatior) di gunakan kontrol positif yaitu dengan antibiotik kloramfenikol dalam bentuk tablet, hasil yang didapatkan terdapat pada gambar berikut.

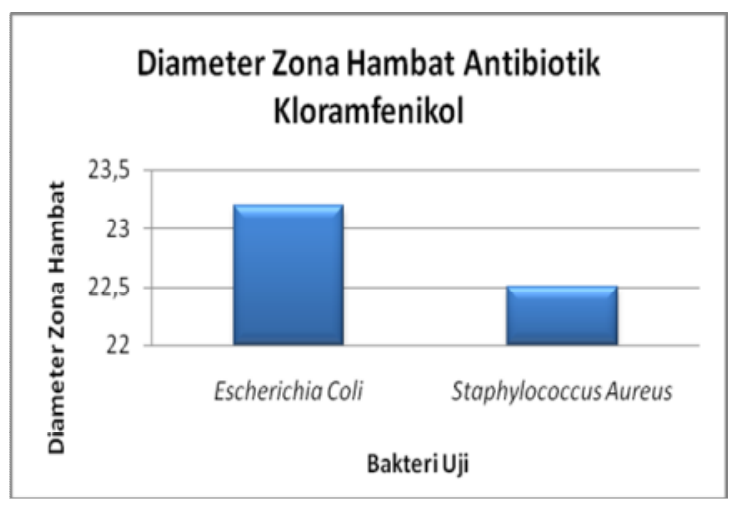

Gambar 4. Grafik diameter zona hambat antibiotik kloramfenikol

Pada pengujian antibakteri menggunakan antibiotik kloramfenikol terlihat bahwa diameter zona hambat yang telah dihasilkan lebih besar dibandingkan diameter zona hambat yang dihasilkan oleh ekstrak air bunga kecombrang (Etlingera elatior). Zona hambat yang dihasilkan oleh E. coli pada antibiotik kloramfenikol dengan nilai rata-rata $23.2 \mathrm{~mm}$ dan pada $S$. aureus mencapai 22.5 $\mathrm{mm}$, sedangkan zona hambat yang dihasilkan oleh S. aureus pada konsentrasi $100 \%$ sebesar $13.89 \mathrm{~mm}$, dan pada E. coli sebesar $7.3 \mathrm{~mm}$.

\section{Kontrol Negatif}

Dalam pengujian antibakteri ekstrak air bunga kecombrang (Etlingera elatior) digunakan kontrol negatif menggunakan aquades, dengan hasil yang diperoleh seperti pada tabel di bawah ini :

Tabel 1. Zona hambat kontrol negatif aquades

\begin{tabular}{|l|c|}
\hline \multicolumn{1}{|c|}{ Bakteri Uji } & Diameter Zona Hambat \\
\hline Escherichia coli & 0 \\
\hline Staphylococcus aureus & 0 \\
\hline
\end{tabular}

Pada pengujian antibakteri terhadap ekstrak air bunga kecombrang (Etlingera elatior) selain menggunakan antibiotik kloramfenikol sebagai kontrol positif, digunakan pula aquades sebagai kontrol negatif. Pengujian menggunakan kontrol negatif tidak didapatkan diameter zona hambat, hal ini dikarenakan aquades tidak dapat menghambat bakteri uji yang digunakan dalam penelitian.

\section{Hasil Analisa GCMS}

Hasil analisa GCMS ekstrak air bunga kecombrang terlihat pada gambar 5 . Berdasarkan hasil analisa GCMS terhadap ekstrak air bunga kecombrang terdapat sedikitnya 6 golongan senyawa utama yang 
terkandung dalam ekstrak ait bunga kecombrang, yaitu alkana, alkena, alkohol, asam lemak, ester, dan fenol. Tiga diantaranya memiliki luas puncak yang paling besar yaitu 1-dodekanol (1) pada waktu retensi 11,60, luas puncak 11,73 dan lemiripan $95 \%$, 3- metil-1-okso-2-buten $\quad$-(- $\left(2^{1}, 4^{1}, \quad 5^{1}\right.$-trihidroksi fenil) (2) pada waktu retensi 13,02, luas puncak 3,17 dan kemiripan $57 \%$ serta 1tetradekena (3) pada waktu retensi 13,26 , luas puncak 6,03 dan lemiripan $98 \%$.

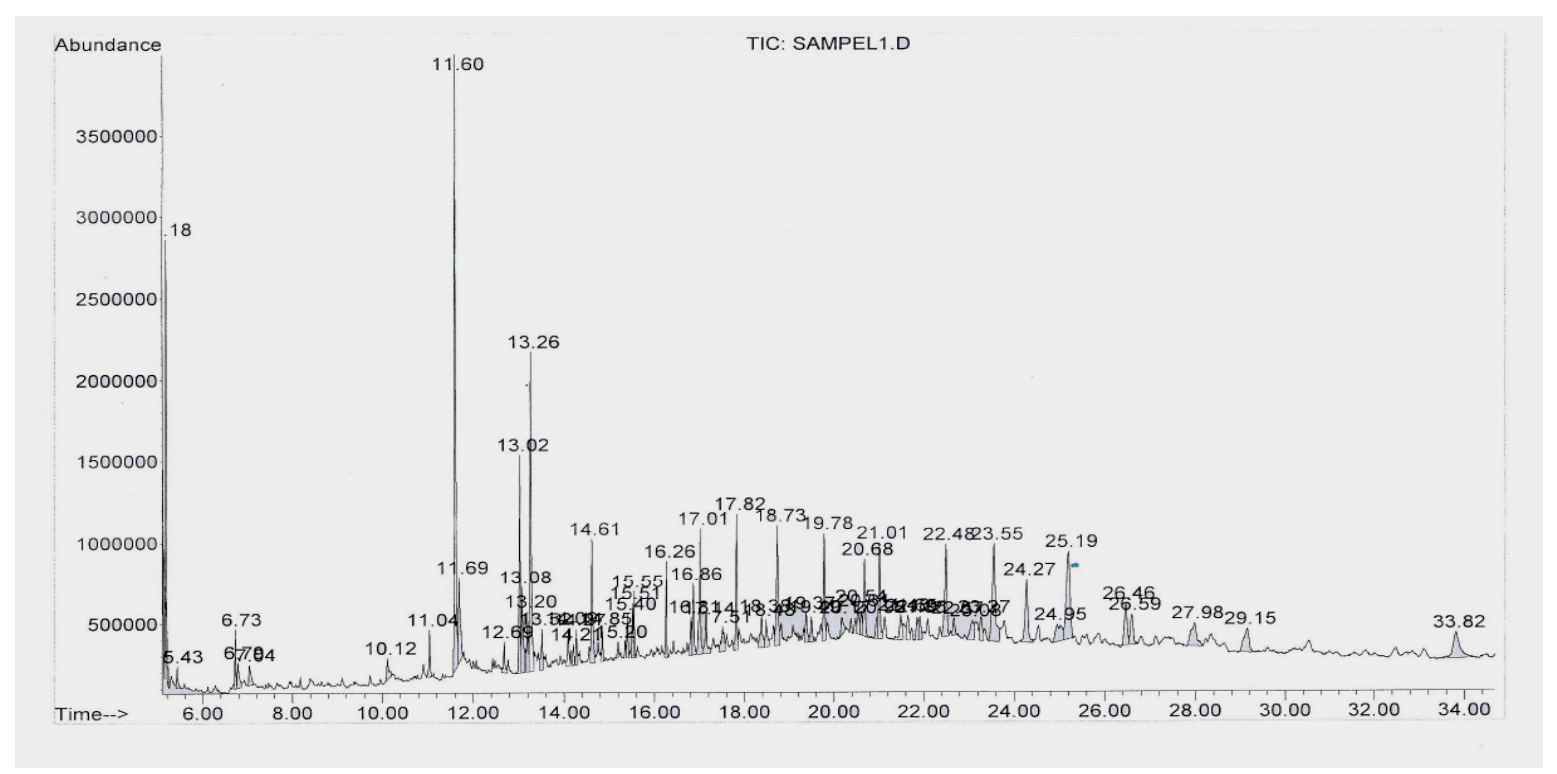

Gambar 5. Hasil analisa GCMS ekstrak air bunga kecombrang (Etlingera elatior)

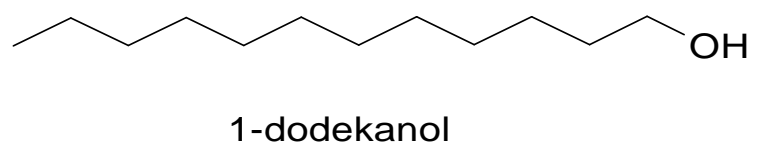<smiles>CC(C)/C=C/Oc1cc(O)c(O)cc1O</smiles>

3-metil-1-okso-2-buten-1-(2 ${ }^{1}, 4^{1}, 5^{1}$-trihidroksi fenil)

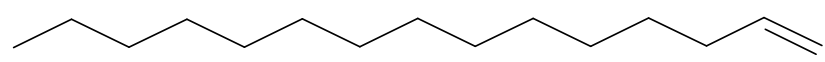

1-tetradekena

Gambar 6. Senyawa utama dalam ekstrak air bunga kecombrang 


\section{KESIMPULAN DAN SARAN}

Kesimpulam dari penelitian ini adalah:

- Ekstrak air bunga kecombrang bersifat antibakteri terhadap E. Coli (zona hambat $4,8 \mathrm{~mm} / 60 \%$ ) dan $S$. Aureus (zona hambat $6,87 \mathrm{~mm} / 20 \%$ ).

- Ekstrak air bunga kecombrang memiliki komponen utama1-dodekanol $(\mathrm{tR}=11,60$, area $=11,73$,kemiripan $95 \%)$, 3-metil-1okso-2-buten 1-( $2^{1}, 4^{1}, 5^{1}$-trihidroksi fenil) $(\mathrm{tR}=13,02$, area $=3,17$ kemiripan $57 \%$ ) dan 1-tetradekena $\quad(\mathrm{tR}=13,26, \quad$ area $=6,03$, kemiripan $98 \%$.

\section{UCAPAN TERIMAKASIH}

Ucapan terimakasih disampaikan kepada Ketua Lembaga Penelitian UIN Syarif Hidayatullah yang telah memberi bantuan dana penelitian BLU UIN Syarif Hidayatullah Jakarta, Ketua Pusat Laboratorium Terpadu (PLT) UIN Syarif Hidayatullah jakarta yang telah memfasilitasi penelitian. Balai Tanaman Obat dan Aromatik- Balai Penelitian Tanaman Rempah dan Obat (BALITRO) Kampus Penelitian Cimanggu, Bogor, Pusat Laboratorium Forensik POLRI Kebayoran Baru Jakarta Selatan, dan Laboratorium Badan Pengkajian dan Penerapan Teknologi (BPPT) Jakarta.

\section{DAFTAR PUSTAKA}

1. Astawan, M. 2003. Pangan fungsional untuk kesehatan yang optimal. Kompas Sabtu 23 Maret 2003.

2. Blois, MS, Antioxidant determinations by the use of a stable free radical, Nature 181, 1958, 1199- 1200.

3. Chan, E.W.C., Lim, Y.Y. \& Omar, M. 2007. Antioxidant and antibacterial activity of leaves of Etlingera species (Zingiberaceae) in Peninsular Malaysia. Food Chemistry 104: pp. 1586-1593.

4. Goldberg, I. 1994. Functional Foods, Designer Foods, Pharmafoods, Nutraceuticals. Chapman \& Hall, London.

5. Habsah, M., Lajis, N.H., Sukari, M.A., Yap, Y.H., Kikuzaki, H. Nakatani, N. \& Ali, A.M.. 2005. Antitumour-Promoting and Cytotoxic
Constituentss of Etlingera Elatior. Malaysian Journal of Medical Sciences, 12 (1). pp. 6-12.

6. Hidayat SS, Hutapea JR. 1991. Inventaris tanaman Obat Indonesia. Edisi I: 440-441. Badan Penelitian dan Pengembangan Departemen Kesehatan Republik Indonesia.

7. Waluyo, L. 2004. Mikrobiologi Umum. Universitas Muhammadiyah Malang. Malang.

8. Winarti, C. \& Nurdjanah, N. 2005. Peluang tanaman rempah \& obat sebagai sumber pangan fungsional. Jurnal Litbang Pertanian 24(2) : 47 -55 . 